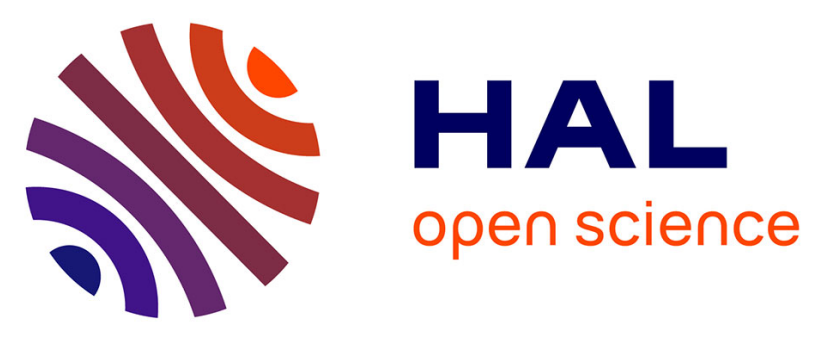

\title{
Correlation of serum hepatitis B core-related antigen with hepatitis B virus total intrahepatic DNA and covalently closed circular-DNA viral load in HIV-hepatitis B coinfection
}

Lorenza N C Dezanet, Sarah Maylin, Audrey Gabassi, Hayette Rougier, Patrick Miailhes, Caroline Lascoux-Combe, Julie Chas, Pierre-Marie Girard, Constance Delaugerre, Fabien Zoulim, et al.

\section{- To cite this version:}

Lorenza N C Dezanet, Sarah Maylin, Audrey Gabassi, Hayette Rougier, Patrick Miailhes, et al.. Correlation of serum hepatitis B core-related antigen with hepatitis B virus total intrahepatic DNA and covalently closed circular-DNA viral load in HIV-hepatitis B coinfection. AIDS. Official journal of the international AIDS Society, 2020, 34 (13), pp.1943-1949. 10.1097/QAD.0000000000002659 . hal-03157376

\section{HAL Id: hal-03157376 \\ https: / hal.sorbonne-universite.fr/hal-03157376}

Submitted on 3 Mar 2021

HAL is a multi-disciplinary open access archive for the deposit and dissemination of scientific research documents, whether they are published or not. The documents may come from teaching and research institutions in France or abroad, or from public or private research centers.
L'archive ouverte pluridisciplinaire HAL, est destinée au dépôt et à la diffusion de documents scientifiques de niveau recherche, publiés ou non, émanant des établissements d'enseignement et de recherche français ou étrangers, des laboratoires publics ou privés. 
TITLE PAGE

2 Correlation of serum hepatitis B core-related antigen with HBV total intrahepatic DNA

3 and ccc-DNA viral load in HIV-hepatitis B coinfection

4

5 Running head: HBcrAg and intrahepatic HBV-DNA viral load

6

7 Lorenza N. C. DEZANET ${ }^{1}$, Sarah MAYLIN², Audrey GABASSI ${ }^{2}$, Hayette ROUGIER ${ }^{3}$, Patrick

8 MIAILHES $^{4}$, Caroline LASCOUX-COMBE 5 , Julie $\mathrm{CHAS}^{6}$, Pierre-Marie GIRARD ${ }^{7}$, Constance

9 DELAUGERRE 2 , Fabien ZOULIM ${ }^{8}$, Karine LACOMBE $^{1,7}$, Anders BOYD $^{7}$

11 Institutional affiliations :

12 'Sorbonne Université, INSERM, Institut Pierre Louis d'Épidémiologie et de Santé Publique, 13 IPLESP, F75012, Paris, France

$14{ }^{2}$ APHP, Hôpital Saint-Louis, Laboratoire de Virologie, Paris, France; Université de Paris,

15 INSERM U944, Institut de Recherche Saint-Louis, F75010, Paris, France

16 3IMEA, Institut de Médecine et d'Epidémiologie Appliquée, Paris, F75018, France

$17{ }^{4}$ Hôpital de la Croix-Rousse, Hospices Civils de Lyon, Service de Maladies Infectieuses,

18 Lyon, F69317, France

$19{ }^{5}$ APHP, Hôpital Saint-Louis, Service de Maladies Infectieuses, Paris, F75010, France

$20{ }^{6}$ APHP, Hôpital Tenon, Service de Maladies Infectieuses, Paris, F75020, France 
$21{ }^{7}$ APHP, Hôpital Saint-Antoine, Service de Maladies Infectieuses et Tropicales, Paris,

22 F75012, France

$23{ }^{8}$ Centre de Recherche sur le Cancer de Lyon, INSERM, Unité 1052, CNRS, UMR 5286, Lyon,

24 France.

25

26 Correspondence and Requests for Reprints to:

27 Dr. Anders Boyd

28 Services de Maladies Infectieuses et Tropicales, Hôpital Saint-Antoine

29184 Rue du Faubourg St. Antoine, 75571 Paris Cedex 12, France

$30 \quad$ Tel: +33171970517

31 Fax: +33149282149

32 Email: anders.boyd@iplesp.upmc.fr

33

34 Conflicts of Interest and Source of Funding: All authors have no potential conflicts of

35 interest, be it financial, professional or personal, that are relevant to the manuscript. This

36 work was supported by SIDACTION (AO 19) and the France REcherche Nord\&sud Sida-hiv

37 Hépatites (ANRS). Gilead Sciences, Inc. provided an unrestricted grant for the French HIV-

38 HBV cohort and was not involved in any part of the data collection, analysis and

39 manuscript writing.

40

41 Word count: Abstract -250 ; Text -1800 


\section{Abstract}

Objective: To assess whether quantified hepatitis $\mathrm{B}$ core-related antigen (qHBcrAg) is a surrogate marker of intrahepatic replication in HIV and hepatitis B virus (HBV) coinfection.

Design: Cross-sectional study of 31 HIV-HBV-infected patients (total liver biopsies, $n=38$ ) from a well-defined cohort.

Methods: Spearman's rank correlation coefficients were calculated between qHBcrAg and intrahepatic markers of HBV replication [total intrahepatic (IH)-DNA, covalently-closed circular (ccc) DNA, cccDNA:total IH-DNA ratio].

Results: At biopsy, 22 (71.0\%) patients were hepatitis B "e" antigen (HBeAg)-positive, 22 (71.0\%) had detectable plasma HBV-DNA and 17 (54.8\%) were treated with tenofovir. Median levels (interquartile range) of intrahepatic markers were as follows: HBV cccDNA ( $n=34), 0.26$ copies/cell (0.4-2.89); total IH-DNA ( $n=38), 2.38$ copies/cell (0.58-207.9), and cccDNA:total IH-DNA ratio $(n=34), 0.05$ (IQR=0.01-0.12). There was a significantly strong correlation between qHBcrAg and cccDNA in all patients (Rho=0.65, $p<0.001$ ), while a moderate correlation was observed between qHBcrAg and total IH-DNA (Rho=0.57, $p<0.001$ ) or cccDNA:total IH-DNA ratio (Rho $=-0.45, p=0.01$ ). Similar findings were observed for HBeAg-positive patients and those with detectable HBV-DNA, with the exception of qHBcrAg and cccDNA or cccDNA:total IH-DNA ratio. In contrast, no significant correlation between qHBcrAg and any intrahepatic marker was observed in HBeAg-negative patients 
63 or those with undetectable HBV-DNA. No significant difference was observed in median

64 qHBcrAg levels across liver fibrosis stages $(p=0.5)$.

65 Conclusions: qHBcrAg is a potential surrogate marker of cccDNA in HIV-HBV co-infected

66 patients, yet might be less useful with undetectable serum HBV-DNA or HBeAg-negative

67 status. Whether qHBcrAg provides further clinical utility compared to other serological

68 markers remains debatable.

69

70 Key words: biomarker; cccDNA; intrahepatic DNA; hepatitis B core-related antigen;

71 hepatitis B virus; HIV.

72

73 
6

\section{Introduction}

In human immunodeficiency virus (HIV)-positive individuals, untreated co-infection with hepatitis B virus (HBV) leads to accelerated liver fibrosis and higher rates of hepatocellular carcinoma and end-stage liver disease[1]. The recommended treatment for chronic HBV in HIV-positive individuals is currently antiretroviral therapy (ART) including a potent nucleos(-t)ide analogue (NA), such as tenofovir (TDF) or tenofovir alafenamide, both of which have dual activity against circulating HBV and HIV[2]. The ultimate goal of treating HBV infection is the clearance of hepatitis B surface antigen (HBsAg), which is associated with histological improvement, reduced risk of hepatocellular carcinoma and prolonged survival[3]. Nevertheless, very few treated HIV-HBV-co-infected individuals are expected to achieve HBsAg-seroclearance[4,5].

In patients with serologic evidence of HBsAg-seroclearance and acquiring HBs antibodies, covalently closed circular (ccc)DNA can still be detected in infected hepatocytes[6], suggesting continued viral activity despite achieving this endpoint. The formation of cccDNA, an episomal minichromosome that serves as a transcriptional template for the production of new HBV progeny, is a crucial step in the HBV life cycle. As such, its presence indicates active HBV replication in the liver and is responsible for viral persistence during chronic hepatitis $\mathrm{B}[6-8]$. However, as the assessment of cccDNA requires an invasive liver biopsy, the development of novel serum biomarkers that 
95

96

97

98

99

100

101

102

103

104

105

106

107

108

109

110

111

112 then to examine the correlation of qHBcrAg and intrahepatic HBV viral loads, including

113 total intrahepatic (IH)-DNA, cccDNA and the ratio between ccCDNA and total IH-DNA, in

114 HIV-positive patients co-infected with chronic HBV.

accurately assess the size of the intrahepatic cccDNA pool and intrahepatic transcriptional activity are needed.

Lower levels of quantified hepatitis B core-related antigen (qHBcrAg) have been shown to bear a strong association with HBeAg-seroclearance for both HBV-mono-infected and HIVHBV-co-infected patients undergoing NA treatment $[9,10]$. This novel surrogate marker has also been found to strongly correlate with the size of the cccDNA pool[11-17]. Recent research has shown that qHBcrAg reflects cccDNA transcriptional activity more strongly than quantified HBsAg (qHBsAg)[18]. Nevertheless, these studies were conducted in HBVmono-infected patients, mainly from Asian countries, where HBV genotypes B and C predominate. Considering that immunological control of intrahepatic HBV is impaired in HIV-HBV-co-infection and stronger degrees of immunosuppression are associated with higher cccDNA levels[1,8], the correlation between $\mathrm{qHBcrAg}$ and intrahepatic replication could be different in co-infected individuals.

Unfortunately, no previous study has investigated to what extent qHBcrAg is able to reflect intrahepatic HBV replication for HIV-HBV-co-infection. The aim of this study was 115 


\section{Methods}

119 Using data from the French HIV-HBV Cohort Study[19,20], we selected patients included in a sub-study on novel markers of HBV replication[9]. Inclusion criteria were as follows: HIV-

121 positive serology confirmed by western blot, HBsAg-positive serology for at least six

122 months, and available quantification of serum HBcrAg and HBV intrahepatic markers from

123 at least one liver biopsy. All patients provided written informed consent and the protocol

124 was approved by the Hôpital Pitié-Salpêtrière and Hôpital Saint-Antoine Ethics

125 Committees (Paris, France) in accordance with the Helsinki Declaration.

127 Serum HBV-DNA was quantified using a real-time PCR assay (COBAS ${ }^{\circledR}$ AmpliPrep/COBAS $^{-1}$

$128 \operatorname{TaqMan}^{\circledR}$, detection limit: $12 \mathrm{IU} / \mathrm{mL}$; or $\operatorname{COBAS}^{\circledR}$ Amplicor HBV Monitor, detection limit: 60

$129 \mathrm{IU} / \mathrm{mL}$; Roche Diagnostics, Meylan, France). qHBsAg was performed using the ARCHITECT

$130 \mathrm{HBsAg}$ assay (Abbott Laboratories, Rungis, France)[5]. qHBcrAg (U/mL) was measured

131 using a commercially-available, automated HBcrAg chemiluminescence enzyme

132 immunoassay (Lumipulse ${ }^{\circledR}$ G System, FujiRebio Europe, Gent, Belgium)[21]. Liver biopsies

133 were obtained based on concomitant guidelines from the European Association for the

134 Study of the Liver [3]. DNA was extracted from snap-frozen biopsy specimens using the

135 MasterPure DNA purification kit (Epicentre, Le-Perray-en-Yvelines, France). cccDNA and 
136 total IH-DNA levels were quantified by real-time PCR using a LightCycler instrument

137 (Roche Diagnostics, Mannheim, Germany) as described previously[6,8].

139 In statistical analysis, HBV-DNA, qHBcrAg, qHBsAg, total IH-DNA and cccDNA were $\log _{10}$

140 transformed. Spearman's rank correlation coefficients were calculated comparing each

141 intrahepatic marker of HBV replication (total IH-DNA, cccDNA, or cccDNA:total IH-DNA

142 ratio) to each serum marker (HBV-DNA, qHBcrAg, or qHBsAg). Analysis was stratified on

$143 \mathrm{HBeAg}$-status and detection of serum HBV-DNA ( $\geq 60 \mathrm{IU} / \mathrm{mL},<60 \mathrm{IU} / \mathrm{mL}$ ). The Kruskal-

144 Wallis test was used to compare median levels of qHBcrAg at different stages of liver

145 fibrosis (Metavir F0-F1, F2, and F3-F4). Scatterplots were used to illustrate the decline of

146 qHBcrAg, cccDNA and total IH-DNA in individuals with paired biopsies during TDF-

147 containing-ART. All statistical analysis was performed using STATA statistical software

148 (v15.1, College Station, TX, USA) and significance was defined as a $p$-value $<0.05$.

150 Results

152 In total, 31 patients (with 38 liver biopsies) were included. Patients were predominately

153 male (90.3\%) with median age of 42 years (IQR=37-53). Only two patients were ART-naïve 154 and six (19.4\%) had HIV-RNA >50 copies/mL. Median CD4+ cell count was fairly high at $155448 / \mathrm{mm}^{3}$ (IQR=331-641), yet 8 patients (25.8\%) ever had an AIDS-defining illness and 156 nadir CD4+ cell count was a median 262/mm $\mathrm{mm}^{3}$ (IQR=150-326). 22 (71.0\%) patients were 
157 HBeAg-positive and 22 (71.0\%) had detectable plasma HBV-DNA (median=3.1 $\log _{10} \mathrm{IU} / \mathrm{ml}$, $158 \mathrm{IQR}=2.7-7.1)$. At biopsy, 23 (74.2\%) patients were on an anti-HBV-containing-ART regimen: 159 lamivudine (LAM), $n=4$ (17.4\%); TDF, $n=2$ (8.7\%); LAM+TDF, $n=15$ (65.2\%); LAM+adefovir 160 (ADV), $n=2$ (8.7\%). Previous exposure to an active anti-HBV treatment was observed in 28

161 (90.3\%) patients, with a cumulative median months as follows: LAM, 73.2 (IQR=50.0-91.7); 162 ADV, 11.7 (range=8.4-33.6); TDF, 24.7 (IQR=9.1-31.0); interferon, 6.5 (IQR=3.1-14.3); and 163 pegylated-interferon, 23.2 (range=13.2-33.2). Of those with previous exposure to LAM, $1647 / 28(25 \%)$ patients had developed resistance. Approximately $30 \%$ of participants $(N=9)$ 165 had advanced liver fibrosis or cirrhosis (Metavir F3-F4). A complete description of the 166 study population at the time of liver biopsy is provided in Supplemental Digital Content 167 Table S1.

168

169 In the samples taken at the time of biopsy, median qHBcrAg was $5.5 \log _{10} \mathrm{U} / \mathrm{mL}(\mathrm{IQR}=3.1$ -

$1707.0, n=38)$ and median qHBsAg $4.0 \log _{10} \mathrm{IU} / \mathrm{mL}$ (IQR=3.2-4.5; $\left.n=30\right)$. HBV cccDNA was

171 available for 27 patients (in 34 liver biopsies) and was a median 0.26 copies/cell (IQR=0.04, 172 2.89) or $-0.59 \log _{10}$ copies/cell (IQR=-1.46, 0.46). Total IH-DNA was available for all 31

173 patients (in 38 liver biopsies) and was a median 2.38 copies/cell $($ IQR=0.58, 207.9) or 0.38

$174 \log _{10}$ copies/cell (IQR=-0.24, 2.32). Median cccDNA:total IH-DNA ratio was 0.05 (IQR=0.01, $1750.12, n=34)$. 
177 As shown in Table 1, there was a significant and strong correlation between qHBcrAg and 178 cccDNA in all patients (Rho=0.65, $p<0.001$; Figure $1 \mathrm{~A}$ ), while a moderate correlation was 179 observed between qHBcrAg and total IH-DNA (Rho=0.57; $p<0.001$; Figure 1B) or $180 \operatorname{cccDNA}$ :total IH-DNA ratio (Rho=-0.45; $p=0.012$; Figure $1 \mathrm{C}$ ). Similar findings were observed

181 for HBeAg-positive patients and those with detectable HBV-DNA, with the exception of no 182 significant correlation between qHBcrAg and cccDNA or cccDNA:total IH-DNA ratio. In 183 contrast, qHBcrAg had no significant correlation with any intrahepatic marker when 184 HBeAg was negative or plasma HBV-DNA was undetectable.

qHBsAg was also significantly and strongly correlated with $\operatorname{cccDNA}(\mathrm{Rho}=0.74, p<0.001)$,

187 total IH-DNA (Rho=0.68, $p<0.001)$ and cccDNA:total IH-DNA ratio (Rho=-0.49, $p=0.009)$ in 188 all patients (Table 1). In contrast, the correlation between qHBsAg and total IH-DNA 189 remained moderate for $\mathrm{HBeAg}$-positive patients, and strong between qHBsAg and total 190 IH-DNA as well as cccDNA for those who were HBeAg-negative. Moreover, in analysis 191 stratified on plasma HBV-DNA, qHBsAg was only strongly correlated with total IH-DNA 192 (Rho=0.80, $p=0.002$ ) when plasma HBV-DNA was undetectable.

194 In 5 of the 7 patients who had two liver biopsies during TDF-containing-ART, a moderately 195 faster rate of qHBcrAg decline was observed in the first three years of treatment and 196 became remarkably slower thereafter (Figure 1D). Similarly, median cccDNA and total IH197 DNA declined from 2.89 copies/cell (range=0.02-8.36) and 45.08 copies/cell (range=0.58- 
198918.95 ) to 0.04 copies/cell (range=0.01-0.305) and 1.40 copies/cell (range=0.32-2.44), 199 respectively, during roughly the first three years of TDF (median 40.2 months, IQR=34.9200 41.6).

201

202 Although a lower median level of qHBcrAg was observed in patients with none or mild 203 liver fibrosis at biopsy (Figure 1E), no significant difference in median qHBcrAg levels was 204 observed across liver fibrosis stages (F0-F1: $4.3 \mathrm{U} / \mathrm{ml}$, IQR=2.6-7.1; F2: $6.4 \mathrm{U} / \mathrm{ml}$, IQR=4.6205 7; F3-F4: $5.2 \mathrm{U} / \mathrm{ml}, \mathrm{IQR}=5-7.5 ; p=0.5)$.

206

207

Discussion

208

209 In our study, we demonstrated a significant and strong correlation overall between 210 qHBcrAg and intrahepatocellular replication, namely levels of cccDNA and total IH-DNA.

211 This would suggest the usefulness of qHBcrAg as a surrogate marker to assess the size of 212 the cccDNA pool and transcriptional activity in HIV-HBV-co-infected patients. This result 213 also corroborates previous findings in HBV-mono-infected population, either 214 untreated $[17,18]$ or during treatment with pegylated-interferon[13,14] or $215 \operatorname{NAs}[11,12,15,16,22]$.

216

217 Nevertheless, other studies in HBV-mono-infected patients have observed significant 218 correlations between qHBcrAg and intrahepatic replication during low-active phases of 
219 HBV infection, that is, when HBV-DNA is undetectable and/or HBeAg is

220 negative[12,17,18,22]. We were unable to confirm these findings in our cohort of HIV-

221 HBV-co-infected patients with HBeAg-negative serology or undetectable serum HBV-DNA.

222 The reasons for these discrepancies are unclear. The majority of studies within the context

223 of HBV-mono-infection were conducted in Asia, where there are substantial differences in

224 viral sequences, replication levels, and disease activity compared to patients from Europe

225 or Africa[23]. HBV genotypes have also been reported to influence the correlation

226 between many markers of HBV replication[15,24] and since our study included mostly

227 patients harboring HBV genotypes $A, D$ and $E$ (as opposed to $B$ and $C$ in many of the Asian,

228 HBV-mono-infection studies), it could be the reason for lack of strong correlation.

229 Alternatively, the lack of correlation could simply be due the small numbers of patients

230 analyzed, contributing to the failure of detecting a significant correlation. It should be

231 noted, however, that the correlations, being between 0.05 to 0.22 , were still quite low.

233 Interestingly, declines in qHBcrAg appeared to tightly coincide with declines in both

234 ccCDNA and total IH-DNA during the first three years of TDF-containing-ART. Although we

235 did not have data on intracellular replication thereafter, no further decline in qHBcrAg was

236 noted. This finding is similar to other markers of replication, such as qHBsAg, and

237 assuming that qHBcrAg remains significantly correlated with cccDNA over time, reinforces

238 that very few patients undergoing long-term treatment with anti-HBV NAs are expected to 239 clear intracellular HBV replication[8]. 
241 Our study has some limitations. The cross-sectional design makes it difficult to infer on

242 correlation of these markers over time and the small sample sizes prohibits further

243 stratification, especially with respect to genotype, precore mutations[25], and levels of

244 CD4+ cell count. Large and multi-center prospective studies would help confirm the

245 present findings, yet as liver biopsies are becoming increasingly rarer in clinical practice,

246 may be unfeasible. In addition, $\mathrm{HBcrAg}$ is a composite biomarker whose assessment may

247 be biased by HBeAg positivity and limited sensitivity, especially at low levels of viral

248 replication. Although $\mathrm{qHBcrAg}$ is mainly correlated with cccDNA transcriptional

249 activity[18], our study could not analyze other intrahepatic viral RNAs because of the lack

250 of samples. Notwithstanding these limitations, we conclude that serum qHBcrAg could be

251 useful in assessing levels of cccDNA, a marker denoting HBV persistence and stability.

252 Nevertheless, the low correlations of this novel surrogate marker with cccDNA levels

253 when serum HBV-DNA is undetectable or HBeAg is negative could limit its clinical

254 practicality. Since the correlations with qHBcrAg observed herein do not seem to surpass

255 those with qHBsAg, it remains debatable whether qHBcrAg provides further clinical utility

256 over qHBsAg. 


\section{Acknowledgements}

This study was sponsored by the Institut de Médecine et d’Epidémiologie Appliquée (IMEA). L.D. was awarded a post-doctoral fellowship from the France REcherche Nord\&sud Sida-hiv Hépatites (ANRS).

Funding. This work was supported by SIDACTION (AO 19) and the ANRS. Gilead Sciences, Inc. provided an unrestricted grant for the French HIV-HBV cohort and was not involved in any part of the data collection, analysis and manuscript writing.

Role of each author. L.D. was responsible for the statistical analysis, interpretation of the data, and drafting the manuscript. S.M. was responsible for $\mathrm{HBcrAg}, \mathrm{HBsAg}$ and $\mathrm{HBeAg}$ quantification, interpretation of the data, and drafting the manuscript. A.G. and C.D. were responsible for $\mathrm{HBcrAg}, \mathrm{HBsAg}$ and $\mathrm{HBeAg}$ quantification and drafted parts of the manuscript. H.R., P.M., C. L-C., and J.C. acquired data for the cohort, assisted in interpreting data, and gave critical revisions of the manuscript. F.Z. gave technical support and provided all biological measurements from liver biopsies, drafted parts of the manuscript, and provided critical revision of the manuscript. P.-M.G. and K.L. helped design, conceptualize, and obtain funding for the French HIV-HBV cohort study, coordinated data collection, and drafted the manuscript. A.B. coordinated data analysis, gave important comments on data interpretation, drafted the manuscript, and provided critical revisions of the manuscript. All authors approved the final version. 


\section{References}

1 Singh KP, Crane M, Audsley J, Avihingsanon A, Sasadeusz J, Lewin SR. HIV-hepatitis B virus coinfection: epidemiology, pathogenesis, and treatment. AIDS 2017; 31:20352052.

$2 \quad$ EACS. Guidelines version 10.0, November 2019.

https://www.eacsociety.org/files/2019_guidelines-10.0_final.pdf (accessed 13 May 2020).

3 European Association for the Study of the Liver. EASL 2017 Clinical Practice

Guidelines on the management of hepatitis B virus infection. J Hepato/2017; 67:370-398.

4 Boyd A, Maylin S, Moh R, Mahjoub N, Gabillard D, Eholié SP, et al. Hepatitis B surface antigen quantification as a predictor of seroclearance during treatment in HIVhepatitis B virus coinfected patients from Sub-Saharan Africa: Seroclearance during treatment. J GastroenterolHepato/2016; 31:634-644.

5 Boyd A, Maylin S, Gozlan J, Delaugerre C, Simon F, Girard P-M, et al. Use of hepatitis B surface and " $\mathrm{e}$ " antigen quantification during extensive treatment with tenofovir in patients co-infected with HIV-HBV. Liver Int 2015; 35:795-804.

6 Werle-Lapostolle B, Bowden S, Locarnini S, Wursthorn K, Petersen J, Lau G, et al. Persistence of cccDNA during the natural history of chronic hepatitis B and decline during adefovir dipivoxil therapy. Gastroenterol 2004; 126:1750-1758.

7 Levrero M, Pollicino T, Petersen J, Belloni L, Raimondo G, Dandri M. Control of cccDNA function in hepatitis B virus infection. J Hepatol 2009; 51:581-592. 
8 Boyd A, Lacombe K, Lavocat F, Maylin S, Miailhes P, Lascoux-Combe C, et al. Decay of ccc-DNA marks persistence of intrahepatic viral DNA synthesis under tenofovir in HIVHBV co-infected patients. J Hepatol 2016; 65:683-691.

9 Dezanet LNC, Maylin S, Gabassi A, Rougier H, Miailhes P, Lascoux-Combe C, et al. Kinetics of hepatitis B core-related antigen and anti-hepatitis B core antibody and their association with serological response in HIV-hepatitis B co-infection. J Inf Dis 2020; 221:1826-1837.

10 Wang B, Carey I, Bruce M, Montague S, Dusheiko G, Agarwal K. HBsAg and HBcrAg as predictors of $\mathrm{HBeAg}$ seroconversion in $\mathrm{HBeAg}$-positive patients treated with nucleos(t)ide analogues. J Viral Hepat2018; 25:886-893.

11 Wong DK-H, Tanaka Y, Lai C-L, Mizokami M, Fung J, Yuen M-F. Hepatitis B Virus Core-Related Antigens as Markers for Monitoring Chronic Hepatitis B Infection. J Clin Microbiol 2007; 45:3942-3947.

12 Suzuki F, Miyakoshi H, Kobayashi M, Kumada H. Correlation between serum hepatitis B virus core-related antigen and intrahepatic covalently closed circular DNA in chronic hepatitis B patients: HBcrAg and cccDNA in Chronic HB Patients. J Med Virol 2009; 81:27-33.

13 Chuaypen N, Posuwan N, Payungporn S, Tanaka Y, Shinkai N, Poovorawan Y, et al. Serum hepatitis B core-related antigen as a treatment predictor of pegylated interferon in patients with HBeAg-positive chronic hepatitis B. Liver Int 2016; 36:827-836. 
14 Chuaypen N, Posuwan N, Chittmittraprap S, Hirankarn N, Treeprasertsuk S, Tanaka $\mathrm{Y}$, et al. Predictive role of serum $\mathrm{HBsAg}$ and $\mathrm{HBcrAg}$ kinetics in patients with $\mathrm{HBeAg}$ negative chronic hepatitis B receiving pegylated interferon-based therapy. Clin Microbiol Infect 2018; 24:306.e7-306.e13.

15 Wang L, Cao X, Wang Z, Gao Y, Deng J, Liu X, et al. Correlation of HBcrAg with Intrahepatic Hepatitis B Virus Total DNA and Covalently Closed Circular DNA in HBeAgPositive Chronic Hepatitis B Patients. J Clin Microbiol 2018; 57:e01303-18, /jcm/57/1/JCM.01303-18.atom.

16 Chen E-Q, Feng S, Wang M-L, Liang L-B, Zhou L-Y, Du L-Y, et al. Serum hepatitis B core-related antigen is a satisfactory surrogate marker of intrahepatic covalently closed circular DNA in chronic hepatitis B. Sci Rep 2017; 7:173.

17 Chen E, Wang M, Tao Y, Wu D, Liao J, He M, et al. Serum HBcrAg is better than HBV RNA and HBsAg in reflecting intrahepatic covalently closed circular DNA. J Viral Hepat 2019; 26:586-595.

18 Testoni B, Lebossé F, Scholtes C, Berby F, Miaglia C, Subic M, et al. Serum hepatitis B core-related antigen (HBcrAg) correlates with covalently closed circular DNA transcriptional activity in chronic hepatitis B patients. J Hepatol 2019; 70:615-625.

19 Boyd A, Gozlan J, Miailhes P, Lascoux-Combe C, Cam MS-L, Rougier H, et al. Rates and determinants of hepatitis B ' $e$ ' antigen and hepatitis B surface antigen seroclearance during long-term follow-up of patients coinfected with HIV and hepatitis 
B virus: AIDS 2015; 29:1963-1973.

20 Lacombe K, Massari V, Girard P-M, Serfaty L, Gozlan J, Pialoux G, et al. Major role of hepatitis B genotypes in liver fibrosis during coinfection with HIV: AIDS 2006; 20:419427.

21 Kimura T, Rokuhara A, Sakamoto Y, Yagi S, Tanaka E, Kiyosawa K, et al. Sensitive Enzyme Immunoassay for Hepatitis B Virus Core-Related Antigens and Their Correlation to Virus Load. J Clin Microbiol 2002; 40:439-445.

22 Wong DK-H, Seto W-K, Cheung K-S, Chong C-K, Huang F-Y, Fung J, et al. Hepatitis B virus core-related antigen as a surrogate marker for covalently closed circular DNA. Liver Int 2017; 37:995-1001.

23 Lin C-L, Kao J-H. Natural history of acute and chronic hepatitis B: The role of HBV genotypes and mutants. Best Pract Res Clin Gastroenterol 2017; 31:249-255.

24 Maasoumy B, Wiegand SB, Jaroszewicz J, Bremer B, Lehmann P, Deterding K, et al. Hepatitis B core-related antigen ( $\mathrm{HBcrAg}$ ) levels in the natural history of hepatitis B virus infection in a large European cohort predominantly infected with genotypes A and D. Clin Microbiol Infect 2015; 21:606.e1-606.e10.

25 Boyd A, Lacombe K, Lavocat F, Miailhes P, Lascoux-Combe C, Girard P-M, et al. Low incidence of precore W28* mutant variants in treated hepatitis B virus and human immunodeficiency virus co-infected patients. Antiviral Res 2018; 149:174-178. 


\section{List of Supplemental Digital Content}

Supplemental Digital Content Table S1.docx 


\section{Figure Subtitle.}

\section{Figure 1.}

Hepatitis B core-related antigen ( $q \mathrm{HBcrAg}$ ) according to (A) HBV covalently-closed circular (ccc)DNA levels, (B) total intrahepatic (IH)-DNA, (C) cccDNA:total IH-DNA ratio, (D) decline of cccDNA and IH-DNA levels for individuals with paired biopsies, and (E) liver fibrosis stages (F0-F1, F2 and F3-F4). 
A

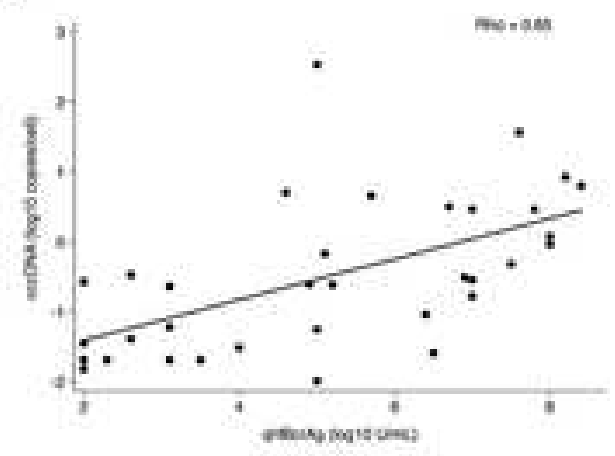

C

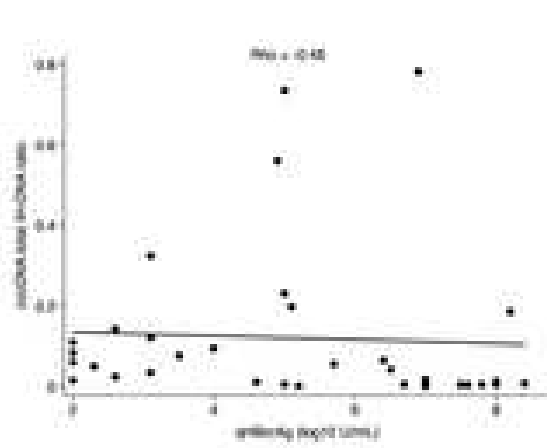

E

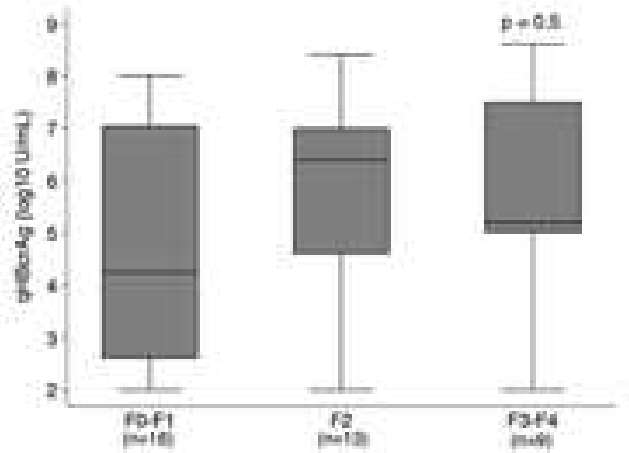

B

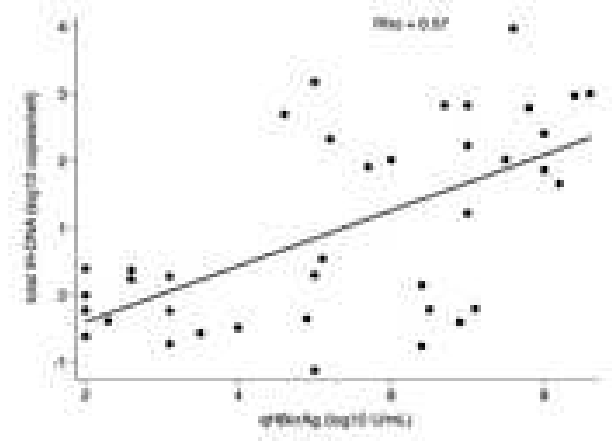

D

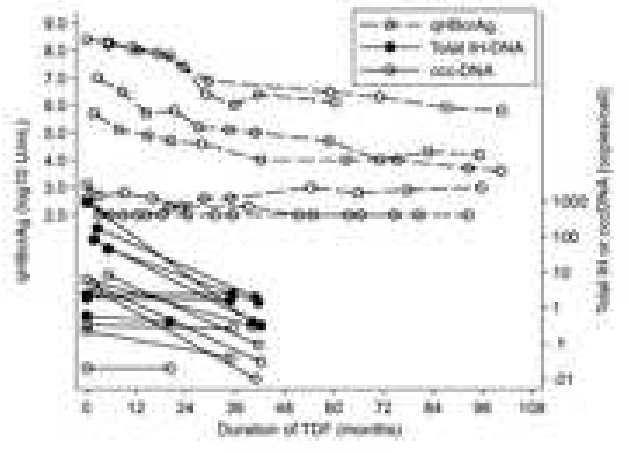

Figure 1. 
Table 1. Correlations between qHBcrAg and intrahepatic viral markers

\begin{tabular}{|c|c|c|c|c|c|c|c|c|c|}
\hline & & total II & DNA & & $\operatorname{cccD}$ & & $\mathrm{CCC}$ & DNA:to & I IH-DNA \\
\hline & $\mathrm{n}^{*}$ & $\mathrm{Rho}^{+}$ & $p$ value & $\mathrm{n}^{*}$ & $\mathrm{Rho}^{+}$ & $p$ value & $\mathrm{n}^{*}$ & $\mathrm{Rho}^{+}$ & $p$ value \\
\hline All liver biops & & & & & & & & & \\
\hline HBV-DNA & 38 & 0.65 & $<0.001$ & $34^{\ddagger}$ & 0.53 & 0.001 & $34^{\ddagger}$ & -0.53 & 0.001 \\
\hline qHBcrAg & 38 & 0.57 & $<0.001$ & $34^{\ddagger}$ & 0.65 & $<0.001$ & $34^{\ddagger}$ & -0.45 & 0.01 \\
\hline qHBsAg & $30^{4}$ & 0.74 & $<0.001$ & $27^{@}$ & 0.68 & $<0.001$ & $27^{@}$ & -0.49 & 0.009 \\
\hline HBeAg-positiv & & & & & & & & & \\
\hline HBV-DNA & 26 & 0.73 & $<0.001$ & $22^{\ddagger}$ & 0.58 & 0.005 & $22^{\ddagger}$ & -0.64 & 0.001 \\
\hline qHBcrAg & 26 & 0.46 & 0.019 & $22^{\ddagger}$ & 0.40 & 0.07 & $22^{\ddagger}$ & -0.48 & 0.02 \\
\hline qHBsAg & 20 ? & 0.59 & 0.006 & $17^{@}$ & 0.42 & 0.10 & $17^{@}$ & -0.40 & 0.11 \\
\hline HBeAg-negati & & & & & & & & & \\
\hline HBV-DNA & 12 & 0.32 & 0.3 & 12 & 0.13 & 0.7 & 12 & -0.06 & 0.9 \\
\hline qHBcrAg & 12 & 0.05 & 0.9 & 12 & 0.22 & 0.5 & 12 & -0.04 & 0.9 \\
\hline qHBsAg & $10^{\text {? }}$ & 0.78 & 0.008 & $10^{\text {\% }}$ & 0.68 & 0.03 & $10^{\circ}$ & 0.08 & 0.8 \\
\hline HBV-DNA $\geq 60$ & & & & & & & & & \\
\hline$(N=23)$ & & & & & & & & & \\
\hline qHBcrAg & 23 & 0.51 & 0.01 & $21^{\ddagger}$ & 0.52 & 0.02 & $21^{\ddagger}$ & -0.37 & 0.10 \\
\hline $\mathrm{qHBsAg}$ & $18^{\pi}$ & 0.42 & 0.08 & $17^{@}$ & 0.44 & 0.08 & $17^{@}$ & -0.21 & 0.4 \\
\hline HBV-DNA $<60$ & & & & & & & & & \\
\hline$(N=15)$ & & & & & & & & & \\
\hline qHBcrAg & 15 & 0.08 & 0.8 & $13^{\ddagger}$ & 0.15 & 0.6 & $13^{\ddagger}$ & 0.02 & 0.9 \\
\hline qHBsAg & $12^{\pi}$ & 0.80 & 0.002 & 10@ & 0.24 & 0.5 & 10@ & -0.28 & 0.4 \\
\hline
\end{tabular}


Data from 38 biopsies: $n=17 \mathrm{HBeAg}$-positive with HBV-DNA $\geq 60 \mathrm{IU} / \mathrm{mL}$; $n=9 \mathrm{HBeAg}$-positive with HBVDNA $<60 \mathrm{IU} / \mathrm{mL}$; $n=6 \mathrm{HBeAg-negative} \mathrm{with} \mathrm{HBV-DNA} \geq 60 \mathrm{IU} / \mathrm{mL}$; and $n=6 \mathrm{HBeAg-negative} \mathrm{with} \mathrm{HBV-DNA}$ $<60 \mathrm{IU} / \mathrm{mL}$. cccDNA, covalently-closed circular DNA; HBV, hepatitis B virus; HBeAg, hepatitis B " $\mathrm{e}$ " antigen; qHBcrAg, quantified hepatitis B core-related antigen; qHBsAg, quantified hepatitis B surface antigen; total IH-DNA, total intra-hepatic-DNA. *Number of available samples in total. 'Spearman's rank correlation coefficient. ${ }^{\ddagger}$ Probes used for ccc-DNA quantification could perform less efficiently with certain strains of HBV genotype $\mathrm{G}$ and were hence considered missing. This concerned 4 liver biopsies: $4 \mathrm{HBeAg-positive}(0$ HBeAg-negative) and 2 with HBV-DNA $\geq 60 \mathrm{IU} / \mathrm{mL}$ (2 with HBV-DNA $<60 \mathrm{IU} / \mathrm{mL}$ ).

ๆNo samples were available to quantify qHBsAg and data were hence missing. This concerned 8 liver biopsies: 6 HBeAg-positive (2 HBeAg-negative) and 5 with HBV-DNA $\geq 60$ IU/mL (3 with HBV-DNA $<60$ $\mathrm{IU} / \mathrm{mL})$.

$@$ Missing data due to HBV genotype G and/or missing sample for $\mathrm{qHBsAg}$. 